\title{
Relatedness and the evolution of mechanisms to divide labour in microorganisms
}

\author{
Ming Liu ${ }^{1}$, Stuart West $^{1}$, and Guy Cooper ${ }^{1}$ \\ ${ }^{1}$ University of Oxford
}

September 24, 2021

\begin{abstract}
Division of labour occurs when cooperating individuals specialise to perform different tasks. In bacteria and other microorganisms, some species divide labour by random specialisation, where an individual's role is determined by random fluctuations in biochemical reactions within the cell. Other species divide labour by coordinating across individuals to determine which cells will perform which task, using mechanisms such as between-cell signalling. However, previous theory, examining the evolution of mechanisms to divide labour between reproductives and sterile helpers, has only considered clonal populations, where there is no potential for conflict between individuals. We used a mixture of analytical and simulation models to examine non-clonal populations and found that: (1) intermediate levels of coordination can be favoured, between the extreme of no coordination (random) and full coordination; (2) as relatedness decreases, coordinated division of labour is less likely to be favoured. Our results can help explain why coordinated division of labour is relatively rare in bacteria, where groups may frequently be non-clonal.
\end{abstract}

\section{Hosted file}

v5.1c_Mechanism_DoL_LowR.docx available at https://authorea.com/users/435246/articles/538401relatedness-and-the-evolution-of-mechanisms-to-divide-labour-in-microorganisms 